\title{
An Optimization Solution for Utilization minibuses Service as an alternative of Utilize Private Cars: A Case Study around Hentian Kajang in Malaysia
}

\author{
Ali Ahmed Mohammed ${ }^{1}$, Riza Atiq O.K.Rahmat ${ }^{2}$ \\ ${ }^{I}$ (Department of Civil and Structural Engineering, Faculty of Engineering/ The National University of Malaysia, 43600 \\ UKM Bangi, Selangor Darul Ehsan, Malaysia ,Assistant Lecturer in Ministry of Higher Education and Scientific Research, \\ Office Reconstruction and Projects / Follow up Department, IRAQ) \\ 2(Department of Civil and Structural Engineering, Faculty of Engineering/ The National University of Malaysia, 43600 \\ UKM Bangi, Selangor Darul Ehsan, Malaysia)
}

\begin{abstract}
In Hentian Kajang many of the problems: traffic congestion, fuel unnecessary loss and global warming are only a few of these problems. This research is an attempt to understand people's behavior and modal choice and try to influence them, and public transport. A survey was conducted to develop a choice between private cars and minibuses and trains users. Have been distributed a total of $\mathrm{n}=25$. Logit models were developed for the alternative modes, private car to minibuses. This study found that the most important variables found likely to encourage the use of public transport were reduced travel time and subsidized fares. The data was processed by SPSS software to determine which factors encourages and discourages using private, public transportation use of minibuses. According to the sensitivity analysis Travel time (0.48), travel cost reduction (0.567), frequency (1.888) the regularity of schedules a key factor for change for use in a minibus when the public viewed in isolation from other factors that limit this option. As expected, for the commuter to switch to minibuses.
\end{abstract}

Keywords - Car reduction, logit model, model shift, public Transport Policy

\section{INTRODUCTION}

Throughout human history the land was known by many changes in climate that scientists have been able to justify most of natural causes, such as some volcanic eruptions or solar fluctuations[16], However the dramatic increase in the temperature of the last year the Earth's surface over the past two centuries (since the start of the industrial revolution)[8].Especially twenty scientists could not be subjected to the same natural causes; where the human activity was during this period a significant impact must be taken into account to explain this steady rise in the Earth's surface temperature or the so-called global warming [2], [21]. In many countries, including Malaysia, transport systems in urban areas, are important elements of the urban fabric. They ensure that people have access to goods and services, jobs and entertainment, to be distributed efficiently and shipping it enables the local economies to prosper[3],[11],[20] .However, if the high density of buildings is the first hallmark of the towns and cities, and large amounts of the movement is now in the second[15],[16]. The movement of significant impacts on the environment and the health of citizens in urban areas, as well as the overall quality of life in cities [4]. A high level of congestion impedes movement, with increased costs for the economy [5], [12]. The government has always been and still trying to improve public transport with different approaches [14].

A sustainable development should provide a transmission system and access to all the urban population in a safe and environmentally friendly transport [1]. This is a complex and difficult when the needs and demands of the people belonging to different income groups [13]. For example, if a large proportion of the population cannot use motorized transport cars - then the government should provide a secure infrastructure for the small buses may need to add some improvements this can be done by increasing the number and cut wages, in terms of the quality of buses as means comfort and come by bus and a small modern airconditioned and do not affect the environment at all [17]. All measures can lead to restriction of movement of users of private cars [13].

\section{LITERATURE REVIEW}

A sustainable development should provide a transmission system and access to all the urban population in a safe and environmentally friendly transport, this is a complex and difficult when the needs and demands of the people belonging to different income groups. For example [21], if a large proportion of the population cannot use motorized transport cars - then the government should provide a secure infrastructure for the small buses may need to add some improvements this can be done by increasing the number and cut wages, in terms of the quality of buses as means comfort and come by bus and a small modern airconditioned and do not affect the environment at all. All measures can lead to restriction of movement of users of private cars. Model shift can be derived from transport demand modeling by changing different factors, influencing the model choice such as transport costs or time of trips [12]. However, such studies are not undertaken to determine a maximum modal shift potential [18]. In most cases they are carried out with the objective of showing the influence of different policies on the transport demand for different 
transport modes. There are a range of models for determining the passenger transport demand in the EU. According to these models can be provisionally subdivided into the following rough groups[5],[11]: Regional input/output models: The demand for transport is supported factors of economic activity in the country and a link between the adoption of the region's economy and transport volume among all regions, Trip Generation (short distance) mobility (national models): such kinds of models are mainly used to determine the trip mobility according to clusters based upon income, household and motorization characteristics for short distances on the national level., Regional gravitational models: these models could be used for regional economy and spatial planning, Logit/Utility based models: these kinds of models attempt to determine a probability of making one or another choice of transport organization[15],[17].

\section{RESEARCH METHODOLOGY}

\section{A. Research Scope}

Many reasons are standing behind making the privet cars most popular mode of travel Such as; travel time, economic factors, reliability and being comfortable [6],[9]. The most acceptable reason for why people prefer privet transport rather than other is car offer opportunities not available by any other means of transport. The previous studies showing us there is minimization in the cost and travel time for the privet cars users, so our challenge is to develop balanced model to reduce the gap between the privet means of transport and the other models [7]. To get a complete transportation planning us should concern about the most prevalent of the road users and how to design convenient and safe ways according to the main factors that affecting the level of service of people; design, location and the users.

\section{B. Research Design}

Research strategy being used is quantitative in character. Basically, this research is based on the primary and secondary data. Following that, the study revolves around the existing Method being used in Malaysia, to gauge uses public transport facilities. After that, case study and analytical Model choice behavior and the shift from private to public transportation mode were analyzed using through data collection being interpreted using SPSS and logit model choice model that approach is mainly used on a local level. The survey information included socio-economic characteristics of individuals, trip information of individuals, and attitudes and perceptions on travel and policy measures [4]. Socio-economic information included household income, individual's income, age, gender, vehicle ownership, and total number of members in household, occupation and education level [6]. Trip information of individuals included the purpose of the trip, mode of travel, total travel time and travel cost ,Improving the Frequency ,Suitable Waiting Time at the Minibus Stops ,Distance for the Residential Located etc. A logic model was developed alternatives namely, bus, train and car, with the aim of comparing the utility of these travel modes and to identify the factors that would influence car users to move from travelling by car to choosing the public transport alternative [9],[19]. The explanatory variables were: age, gender, income, and travel time, travel cost and car ownership

In several counties surveys are carried out concerning the mobility behavior of the population. In such contexts the willingness to undertake a modal shift was rarely surveyed. It is very likely that the train companies, national and public transport companies have such data for analysis, but the competitive aspects of the situation make it difficult to obtain these data. The details of the road user's behavior that we got from the data collection and the procedure of the data analysis to establish the model. Fig. 1 below shows the determinant variables that were used [21].

\section{Data Collection}

Data collection done by the survey, the survey was based on a questionnaire that collected different attributes including age, race, and number of members of the household and level of education, thus giving a clear image of their socioeconomic and demographic profiles. Other information collected includes: level of knowledge (of public transport), travel time, travel cost, number of trips and the preferred mean of transportation A total of 30 questionnaires were distributed and collected throughout the process of data collection. The data was collected by personal interview with car users because they are the target of the study [6].

SPSS analytical system used to determine which parts of the questionnaire were relevant and which were not to each other [7]. The procedure used for the variables assesses the number of commonly used measures and also provides information on the relationships between the individual items in the scale such as gender, nationality, age, household size and mode of transportation and the walking ability the explanatory variables of data collection[7]. 


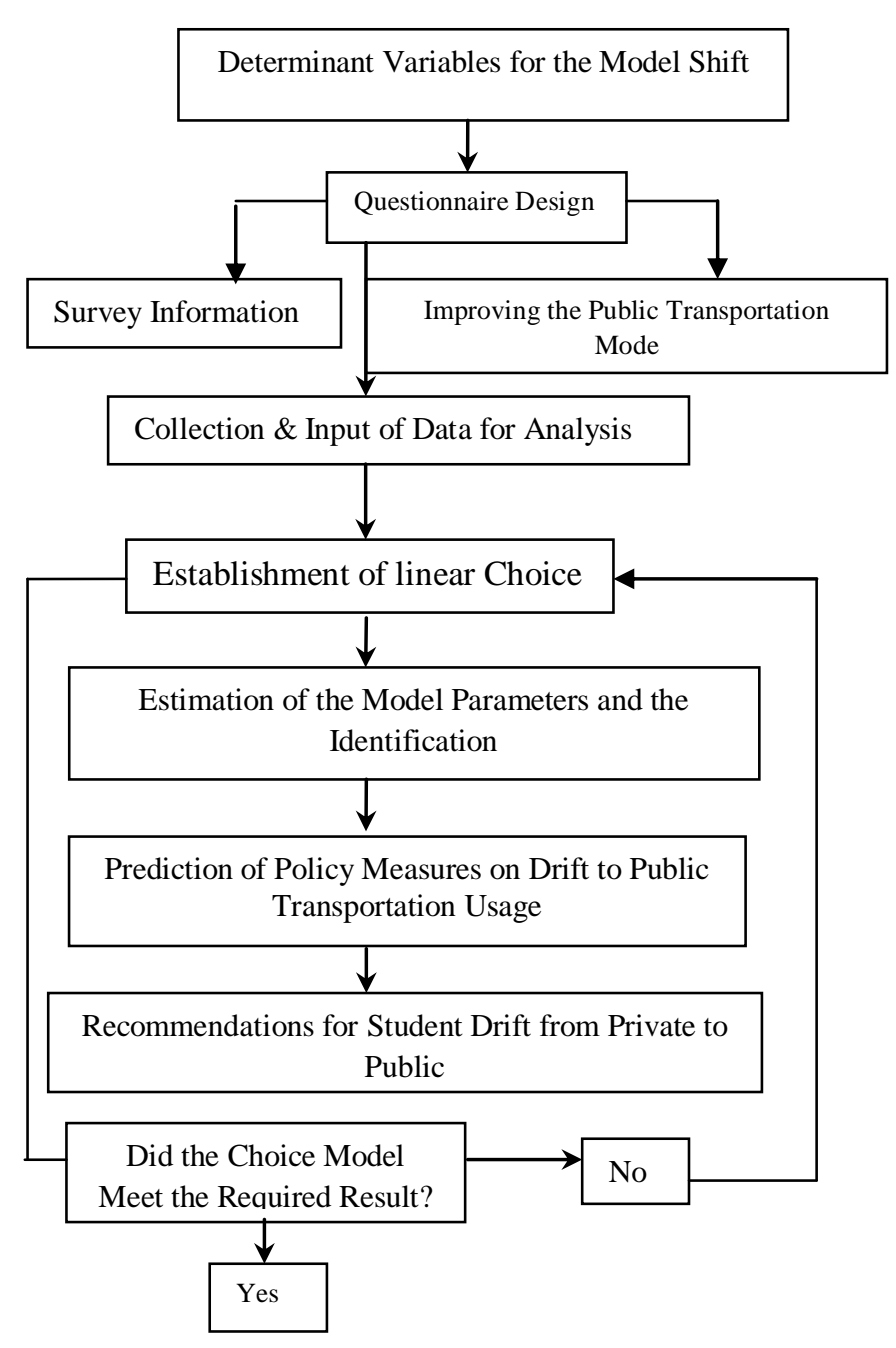

Fig. 1 Design illustration of strategies used for data collection and analysis

\section{MODEL STRUCTURE}

The logit model was used a final model to investigate mode choice behavior of travelers of modes of transport and to determine the tradeoffs travelers make when considering their mode of transport[9],[12]. The proposed model that contained all was used to determine the dependent variables. The logistic functional form is commonly identified as a single-layer "perception" or single-layer artificial neural network. A single-layer neural network computes a continuous output instead of a step function. The derivative of pi with respect to $\mathrm{X}$ is computed from the general form:

$y=\frac{1}{1+e^{-f(X)}}$

Where $\mathrm{f}(\mathrm{X})$ is an analytic function in $\mathrm{X}$. With this choice, the single-layer network is identical to the logistic regression model. This function has a continuous derivative, which allows it to be used in back-propagation[16,7].

The following functional form is used to determine the dependent variables.

$$
\begin{aligned}
& P=\frac{1}{1+D e^{\alpha(\text { variable })}} \\
& P(t, a, m, n, \tau)=a \frac{1+m e^{-t / \tau}}{1+n e^{-t / \tau}}
\end{aligned}
$$

The special case of the logistic function with $\mathrm{a}=1, \mathrm{~m}=0, \mathrm{n}$ $=1, \tau=1$, namely

$$
P(t)=\frac{1}{1+e^{-t}}
$$

For real parameters $\mathrm{a}, \mathrm{m}, \mathrm{n}$, and $\tau$. These functions find applications in a range of fields, including economics [19]. A logistic function or logistic curve is the most common sigmoid curve. It models the "S-shaped" curve (abbreviated S-curve) of growth of some set: Here P denotes a set. Later we will use $P$ to denote a function which varies over time. Normally such a function is written $\mathrm{P}(\mathrm{t})$. However, such a function may also be read as a set of ordered pairs of the form $\langle\mathrm{t}, \mathrm{P}(\mathrm{t})\rangle$. By convention mathematicians are wont to write $\mathrm{P}$ to denote such a set. $P$, where $P$ might be thought of as population. The initial stage of growth is approximately exponential; then, as saturation begins, the growth slows, and at maturity, growth stops [20].

$$
\begin{aligned}
& P(t)=\frac{1}{1+e^{(-t)}}=\frac{1}{1+\exp ^{(-t)}}=(1+\exp (-t))^{-1} \\
& P^{`}=p(1-p)
\end{aligned}
$$

The function $\mathrm{P}$ has the intuitively appealing quality that

$$
1-P(\mathrm{t})=p(-t)
$$

Pilot survey data obtained from question related to proportion of people board on minibus with respective to a series of proposed travel time reduction has been used to calibrate the logit model with var = time factor[14].

$$
P=\frac{1}{1+D e^{\alpha(\mathrm{var})}}
$$

Let $p(t)$ be the probability of success when the value of the predictor variable is $t$. Then let

$P=\frac{1}{1+D e^{\alpha(r)}}$

Algebraic manipulation shows that

$$
\frac{1-P}{P}=D e^{(\alpha \cdot r)}
$$


$\ln \left[\frac{1-P}{P}\right]=\ln D+\alpha^{(r)}$

The above equation investigates the calibration process based on the values of $D$ and $\alpha$ values which were extracted from ANOVA Table using Microsoft Excel. These results applied to the final equation shown below and then the results were used for model validation.

$$
P=\frac{1}{1+D e^{\alpha(\text { variable })}}
$$

\section{RESULTS}

\section{A. Improving the Travel Time for the minibus}

Travel time is considered an important reason for mode choice. Using public minibus services is perceived as a waste of time by almost all private vehicle users. Figure 2 showed that a time reduction of thirty percent in current minibus transportation servicing will attracted $(28 \%)$ of people to board on the minibus while, a time reduction of seventy five percent will attracted (82\%) of people to use the public minibus service, This indicates the possibility of an increase in the use of minibuses service.

\section{TABLE .I}

Improving the Travel Time for the minibus

\begin{tabular}{|c|c|c|c|c|}
\hline Valid & $\begin{array}{c}\text { Frequenc } \\
\mathrm{y}\end{array}$ & Percent \% & $\begin{array}{c}\text { Valid } \\
\text { Percent } \%\end{array}$ & $\begin{array}{c}\text { Cumulative } \\
\text { Percent } \%\end{array}$ \\
\hline $15 \%$ & 6 & 24.0 & 24.0 & 24.0 \\
\hline $30 \%$ & 1 & 4.0 & 4.0 & 28.0 \\
\hline $45 \%$ & 2 & 8.0 & 8.0 & 36.0 \\
\hline $60 \%$ & 3 & 12.0 & 12.0 & 48.0 \\
\hline $75 \%$ & 8 & 32.0 & 32.0 & 80.0 \\
\hline $90 \%$ & 5 & 20.0 & 20.0 & 100.0 \\
\hline Total & 25 & 100.0 & 100.0 & \\
\hline
\end{tabular}

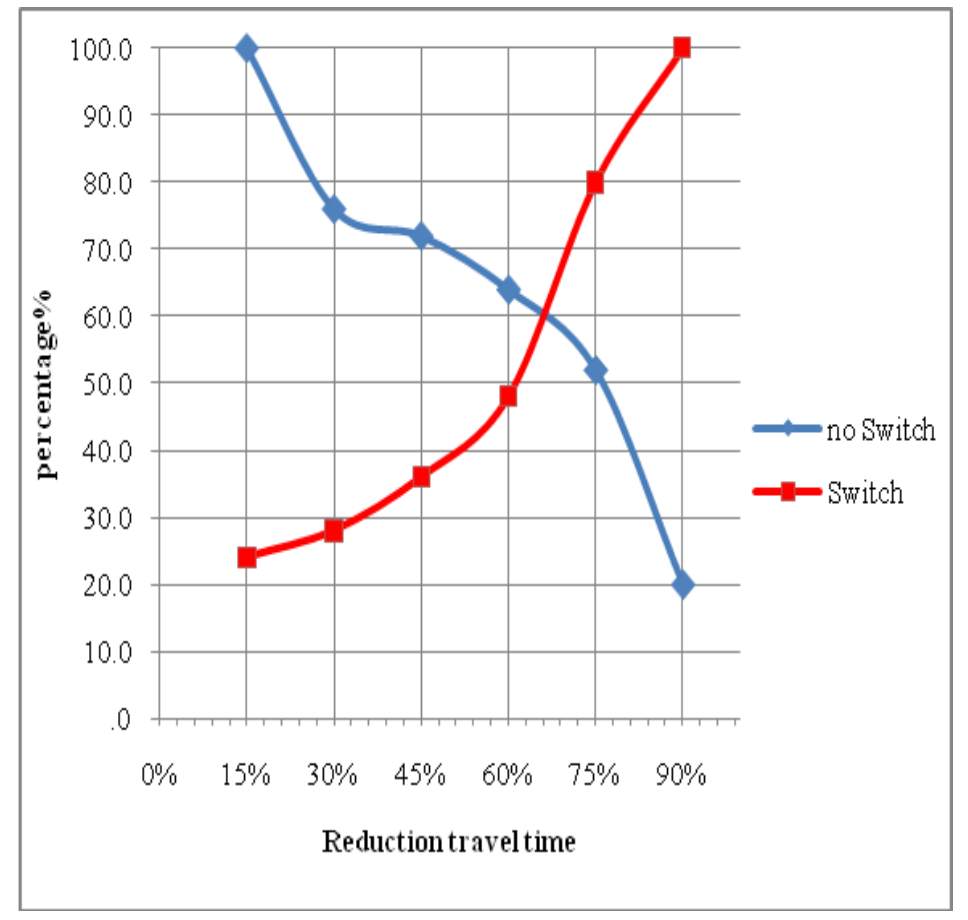

Fig. 2 Switching To Public Transport if the Travel Time Improved By Reduction

TABLE .II An illustration Cumulative Percent \%

\begin{tabular}{|c|c|c|c|}
\hline $\begin{array}{c}\text { Travelling Time } \\
\text { Reduction }\end{array}$ & Survey Results (P) & $(1-\mathrm{P}) / \mathrm{P}$ & $\mathrm{LN}(1-\mathrm{P}) / \mathrm{P}$ \\
\hline $15 \%$ & 0.24 & 3.166667 & 1.15268 \\
\hline $30 \%$ & 0.04 & 24 & 3.178054 \\
\hline $45 \%$ & 0.08 & 11.5 & 2.442347 \\
\hline $60 \%$ & 0.12 & 7.333333 & 1.99243 \\
\hline $75 \%$ & 0.32 & 2.125 & 0.753772 \\
\hline $90 \%$ & 0.2 & 4 & 1.386294 \\
\hline
\end{tabular}

The results shown above reflect the process of calibration which then imported to excel to get the ANOVA table V which is described.

From ANOVA table our model got the value of $\mathrm{P}$ equals to (0.001140754) which somehow acceptable to be significant (significant value <0.05) while is $\mathrm{R}$ Square (0.94537). Show appendix 
TABLE $\quad$.III

An illustration Survey results and logit model result

\begin{tabular}{|c|c|c|}
\hline $\begin{array}{c}\text { Travelling } \\
\text { Time } \\
\text { Reduction }\end{array}$ & $\begin{array}{c}\text { Survey Results } \\
(\mathrm{P})\end{array}$ & $\begin{array}{c}\text { Results from logit } \\
\text { model }\end{array}$ \\
\hline $15 \%$ & 0.24 & 0.229495 \\
\hline $30 \%$ & 0.28 & 0.283403 \\
\hline $45 \%$ & 0.36 & 0.356892 \\
\hline $60 \%$ & 0.48 & 0.456328 \\
\hline $75 \%$ & 0.8 & 0.822283 \\
\hline $90 \%$ & 1 & 0.998536 \\
\hline
\end{tabular}

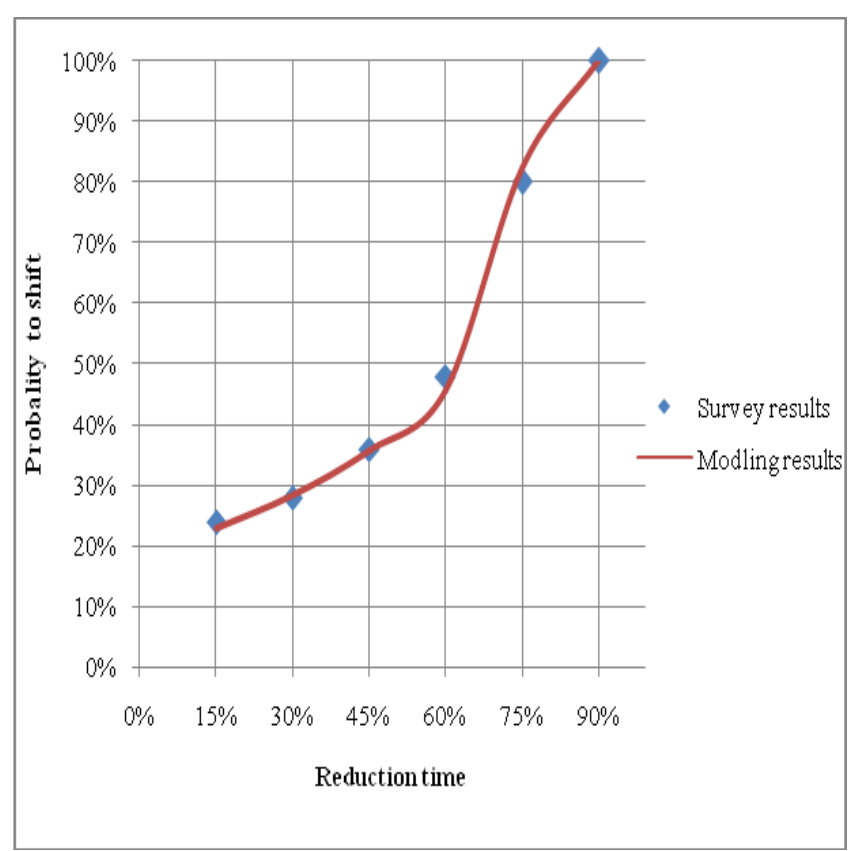

Fig.3. Improving Travel Time for the Bus to encourage minibus uses

\section{B. Improving the Travel Cost}

Money is an important issue. Improving the travel cost for the minibus by reduction it, will be as a motive to encourage the public transportation minibus use. Figure 4 Our survey result shows that $(20 \%)$ of the people will prefer using minibus if there is thirty percent reduction on the fare while, reduction of seventy five percent on the fare will be enough to encourage (84\%) will prefer using public minibus for cost pay for trip the fare will be enough to encourage people to start using the public minibus.

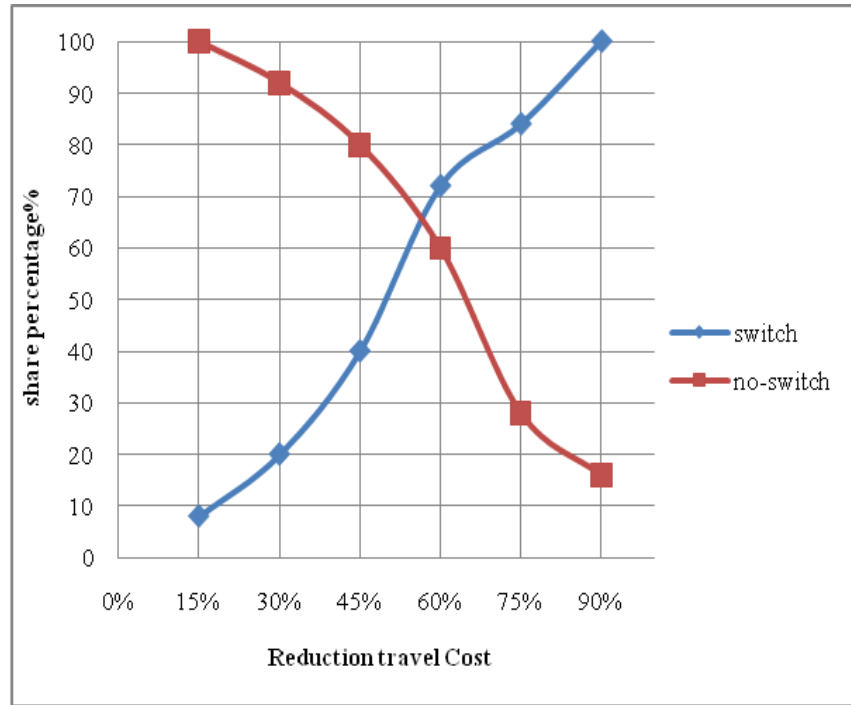

Fig 4 Switching to Public transport if travel cost improved by reduction

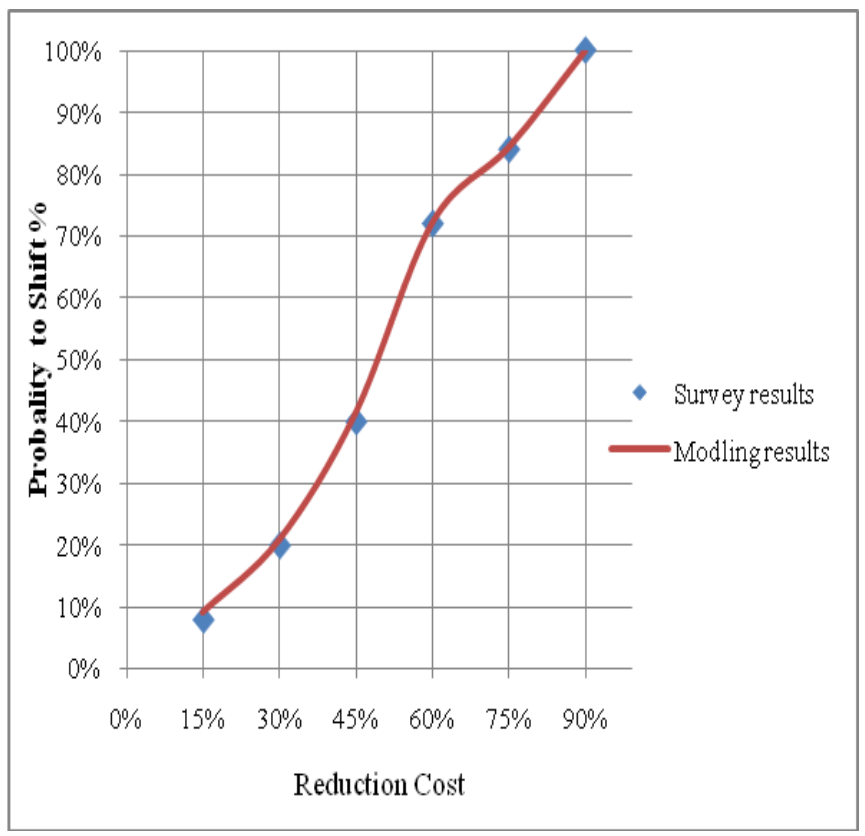

Fig.5. Improving the Travel Cost for the Bus to encourage minibus use

\section{Improving the Frequency}

It is generally acknowledged minibus is cheaper than a private car but does not appear as a key factor for change in a small public bus when viewed in isolation from other factors that limit this option. Figure 6 Our survey result shows that (29\%) of the people will prefer using minibus if there is sixteen percent reduction on the regularity of schedules while, reduction of thirty six percent on the regularity of schedules will be enough to encourage (68\%) will prefer using public minibus. 


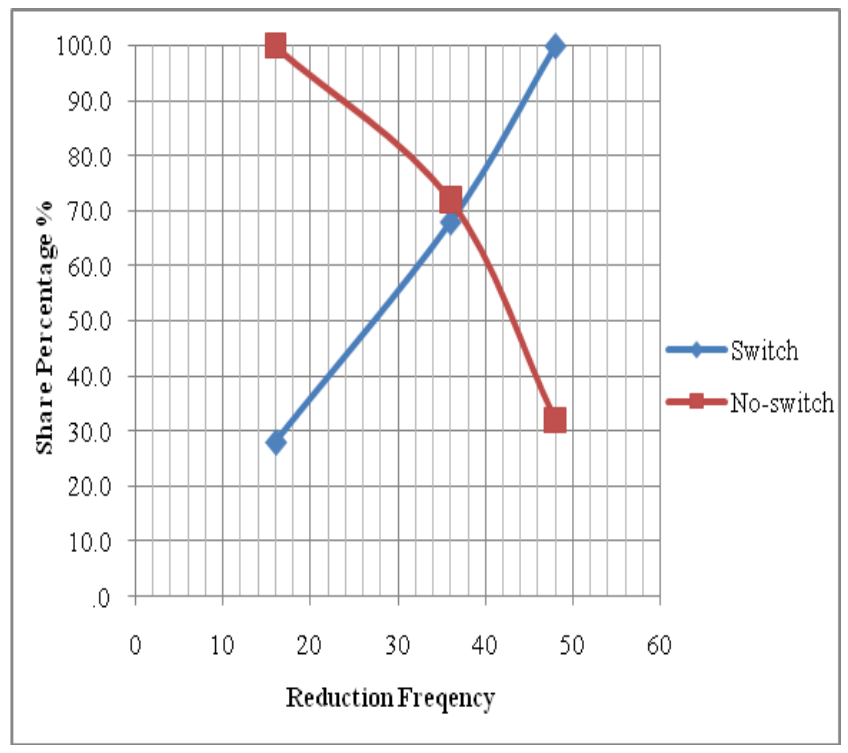

Fig .6.Switching to reduction Frequency

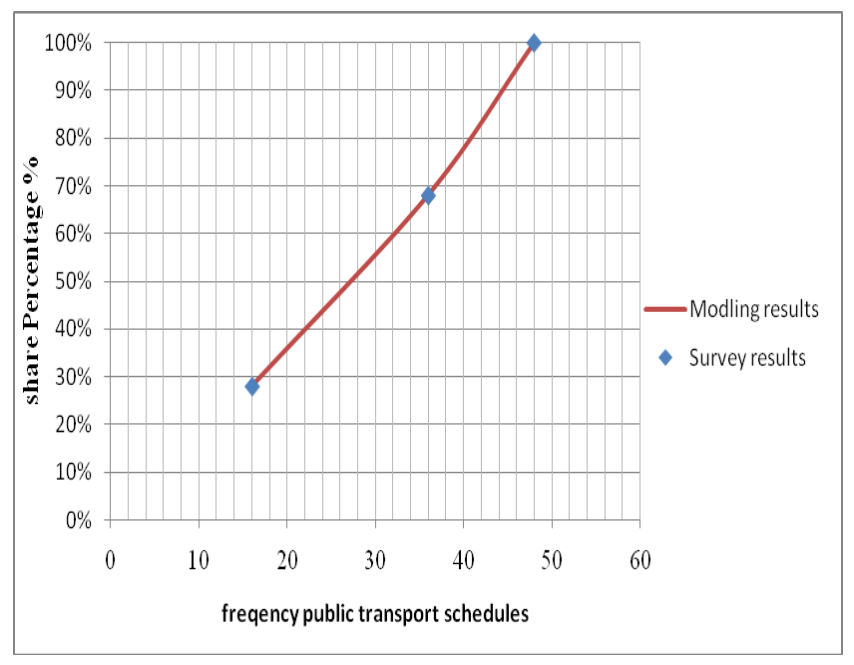

Fig. 7. Improving Frequency public transport schedules

TABLE .IV

Sensitivity Ratio

\begin{tabular}{|c|c|c|}
\hline $\begin{array}{c}\text { Changes in } \\
\text { Independent } \\
\text { Variable }\end{array}$ & $\begin{array}{c}\text { Changes in Dependent } \\
\text { Variable }\end{array}$ & Sensitivity Ratio \\
\hline $\begin{array}{c}75 \% \text { Travel } \\
\text { Time } \\
\text { Reduction }\end{array}$ & $36 \%$ Model Shift & 0.48 \\
\hline $\begin{array}{c}60 \% \text { Travel } \\
\text { Cost reduction }\end{array}$ & $34 \%$ Model Shift & 0.567 \\
\hline $\begin{array}{c}36 \% \\
\text { Frequency }\end{array}$ & $68 \%$ Model Shift & 1.888 \\
\hline
\end{tabular}

\section{SENSITIVITY ANALYSIS}

\section{A. Travel Time reduction}

The sensitivity of the modeling has been tested by taking the public transport services into a calibration. Therefore a further $75 \%$ of increment time reduction for travel public transport will attract $36 \%$ of people to use the public minibus service; this indicates the possibility of an increase in the use of minibuses service. Then the sensitivity ratio is 0.48 .

\section{B. Travel cost reduction}

Reduction of $60 \%$ on the fare will be enough to encourage $34 \%$ will prefer using public minibus for cost pay for trip the fare will be enough to encourage people to start using the public minibus. Then the sensitivity ratio is 0.567 .

\section{CONCLUSION}

To be the use of minibuses alternative than using private cars should take strict measures to develop this sector. To be able to compete with the car, the minibus service must offer the quality desired by regular and potential users. It can be seen that potential users could be the ones who show positive attitudes to public transport. It is important to understand what these individuals want, what is the service attributes most important to them, and what would make them switch to using minibus services.

The Sensitivity ratio is (1.888) is very high ratio possible neglected this ratio. That there was a need to use minibuses modern travelers a means of public transport. Process will be positive to reduce travel time and cost prohibitive, as well as reduce environmental pollution by private cars and better service (more frequent flights and on time) and reduce traffic jams, especially in the (Hentian Kajang), and the other negative is the reduction of parking spaces, increased fees. The consequences of this will be less traffic on the roads that will reduce pollution and increase safety.

\section{ACKNOWLEDGMENT}

Special thanks to Professor Riza Atiq O.K.Rahmat for guidance.

\section{REFERENCES}

[1] Ahn and Cassidy, 2007 S. Ahn and M.J. Cassidy, Freeway traffic oscillations and vehicle lane-change maneuvers, Transportation and Traffic Theory vol. 1, Elsevier (2007), pp. 691-710 .

[2] Angela Hull. 2007. Policy integration: What will it take to achieve more sustainable transport solutions in cities?. School of the Built Environment, Heriot-Watt University.

[3] Abdullah, N., RizaAtiq, \&AmiruddinI . 2007. Modeling of transportation behavior for coercive measures for car driving in Kuala Lumpur. ARPN Journal of engineering and Applied Sciences, VoL 2,No.2,PP.18-24. 
[4] Riza. 2004. Urban Transport Management System, Engineering Faculty, UKM IRPA 04 - 02 - 02 - 0000 - PR59/09.

[5] Think ,up.\&E.Szimba 2002. Passenger transport market: Segmentation, trends and policy conclusionsResults from Think-up,seminar S4"Potentials for modal shift :A segmented Approach for the European transport market",2002.

[6] Ali Ahmed Mohammed, Omar Abdullah Alelweet, Mohamed Rehan Karim and Ouf Abdulrahman Shams," An Optimization Solution by Service Science Management and Engineering (SSME) for Using Minibuses Service as an alternative for Private Cars Around Hentian Kajang in Malaysia" International Journal of Civil Engineering and Construction Technology,USA, ISSN 2141-2634, Vol. 3(1), pp. 2541, January 2012.

[7] Ali Ahmed Mohammed, An Optimization Solution for Using Minibuses Service as an alternative of using Private Cars Around Hentian Kajang in Malaysia,master diss, university Kebangsaan Malaysia,2010.

[8] Garvill, J., Marell, A. \&Nordlund, A. 2003. Effects of increased awareness on choice of travel mode. Transportation 30: 63-79.

[9] Balsas, C., 2003. Sustainable transportation planning on college campuses. Transport Policy 10: 35-49.

[10] Bando et al., 1998 M. Bando, K. Hasebe, K. Nakanishi and A. Nakayama, Analysis of optimal velocity model with explicit delay, Physical Review E 58 (5) (1998), pp. 5429-5435. View Record in Scopus | Cited By in Scopus (83).

[11] Krygsman, S. Dijst, M. 2001. Multimodal trips in the Netherlands: Microlevel individual attributes and residential context. Transportation Research Record 1753, 11-19.

[12] Abdullah, N., RizaAtiq, \&AmiruddinI . 2007. Effect of transportation policies on modal shift from private car to public transport in Malaysia.Journal of applied Sciences, ,VoL .7(7):PP.1013-1018.
[13] Ahern, A. \&Tapley, N. 2007. The use of stated preference techniques to model choices on interurban trips in Ireland. Transportation Research Part A.doi:10.1016/j.tra.2007.06.005.

[14] Angela Hull. 2007. Policy integration: What will it take to achieve more sustainable transport solutions in cities?.School of the Built Environment, Heriot-Watt University.

[15] Axler, R., Chang, W., Gan, J. \&Kembhavi, S. 2006. Out of Cars and Onto Bikes: Encouraging a Modal Shift from Cars to Bicycles at the University of Toronto. ENV 421: Applied Research Seminar 20052006.

[16] Beale, J. \&Bonsall, P. 2007. Marketing in the bus industry: A psychological interpretation of some attitudinal and behavioural outcomes. Transportation Research Part F (10): 271-287.

[17] Black, W. 1997. North American transportation: perspectives on research needs and sustainable transportation. Journal of Transport Geography 5(1): 12-19.

[18] Bos, I. 2004. Changing Seats: A Behavioural Analysis of P\&R Use.PhD Thesis, Delft University of Technology, the Netherlands.

[19] Gershenfeld, Neil. A, 1999. The Nature of Mathematical Modeling .Cambridge,UK:Cambridge University Press .ISBN 978-0521-570954.

[20] Jannedy, Stefanie .Bod , Rens;Hay;Jennifer2003 .Probabilistics .Cambridge,Massachusetts:MIT Press.ISBN 0-262-52338-8 .

[21] Ortuzar. \&Willumsen . 2006. Juan de Dios Ortuzar LuisG.willumsen:Modelling transport, third edition, Canada, John Wiley and Sons,LTD. 
APPENDIX

ANOVA Table for Improving the Travel Time

\section{SUMMARY OUTPUT RESULT}

\begin{tabular}{cc}
\hline \hline \multicolumn{2}{c}{ Regression Statistics } \\
\hline Multiple R & 0.9723 \\
R Square & 0.945 \\
Adjusted R & \\
Square & 0.9317 \\
Standard Error & 0.2347 \\
Observations & 6 \\
\hline
\end{tabular}

ANOVA

\begin{tabular}{cccccc}
\hline & df & SS & MS & F & Significance \\
& & & & & \\
\hline Regression & 1 & 3.81128 & 3.811284 & 69.20205 & 0.00114 \\
Residual & 4 & 0.2203 & 0.055075 & & \\
Total & 5 & 4.03158 & & & \\
\hline
\end{tabular}

\begin{tabular}{ccccccccc}
\hline & Coefficients & $\begin{array}{c}\text { Standard } \\
\text { Error }\end{array}$ & t Stat & P-value & Lower 95\% & Upper & Lower & Upper \\
& & & & & & & & \\
& & & & & & & & \\
\hline Intercept & 3.196 & 0.19139 & 16.6984 & $7.5 \mathrm{E}-05$ & 2.66447 & 3.727216 & 2.6645 & 3.7272 \\
X Variable 1 & -8.269 & 0.99407 & -8.31878 & 0.00114 & -11.0295 & -5.50949 & -11.029 & -5.509 \\
\hline
\end{tabular}

